\title{
Boundary Shift Integral
}

National Cancer Institute

\section{Source}

National Cancer Institute. Boundary Shift Integral. NCI Thesaurus. Code C114183.

A measurement of change in volume of an organ or anatomical feature as determined by a shift in tissue boundary over time. 